Meta

Journal des traducteurs

Translators' Journal

\title{
Translation Typology and the Interdisciplinarity of Translatology
}

\section{Georgios Floros}

Volume 50, numéro 4, décembre 2005

Pour une traductologie proactive - Actes

For a Proactive Translatology - Proceedings

Por una traductología proactiva - Actas

URI : https://id.erudit.org/iderudit/019837ar

DOI : https://doi.org/10.7202/019837ar

Aller au sommaire du numéro

\section{Éditeur(s)}

Les Presses de l'Université de Montréal

\section{ISSN}

0026-0452 (imprimé)

1492-1421 (numérique)

Découvrir la revue

Citer cet article

Floros, G. (2005). Translation Typology and the Interdisciplinarity of Translatology. Meta, 50(4). https://doi.org/10.7202/019837ar
Résumé de l'article

Le présent article examine la question de l'interdisciplinarité de la traductologie, dans son rapport avec celle de la typologie de la traduction. Il y est suggéré que la typologie ne constitue pas seulement une préoccupation théorique centrale inhérente à toute discipline, mais également un pivot important de l'interaction de la traductologie avec d'autres disciplines. Cet article se voudrait une tentative de repenser les types de traduction, cette activité étant l'un des secteurs où l'interdisciplinarité est particulièrement manifeste. Si, jusqu'à présent, d'autres disciplines ont eu leur mot à dire dans la typologie de la traduction et les textes à traduire (telles la linguistique, la théorie des genres), ce sont plutôt des critères propres au champ des études de traductologie qui devraient être retenus afin de constituer une typologie plus éloquente, basée sur le rapport entre le texte et son contexte. 


\title{
Translation Typology and the Interdisciplinarity of Translatology
}

\author{
GEORGIOS FlOROS \\ University of Cyprus, Nicosia, Cyprus \\ gfloros@ucy.ac.cy
}

\begin{abstract}
RÉSUMÉ
Le présent article examine la question de l'interdisciplinarité de la traductologie, dans son rapport avec celle de la typologie de la traduction. Il y est suggéré que la typologie ne constitue pas seulement une préoccupation théorique centrale inhérente à toute discipline, mais également un pivot important de l'interaction de la traductologie avec d'autres disciplines. Cet article se voudrait une tentative de repenser les types de traduction, cette activité étant l'un des secteurs où l'interdisciplinarité est particulièrement manifeste. Si, jusqu'à présent, d'autres disciplines ont eu leur mot à dire dans la typologie de la traduction et les textes à traduire (telles la linguistique, la théorie des genres), ce sont plutôt des critères propres au champ des études de traductologie qui devraient être retenus afin de constituer une typologie plus éloquente, basée sur le rapport entre le texte et son contexte.
\end{abstract}

\begin{abstract}
In this paper the issue of interdisciplinarity in translatology is discussed in relation to the problem of translation typology, and it is suggested that typology is not only a core theoretical issue in any discipline, but also an important point of reference for the interaction of translatology with other disciplines. This paper should be seen as an attempt to rethink the types of translation, as this is, among others, an area where interdisciplinarity finds a sound expression. Up until now other disciplines have set the pace in the typology of translation and the texts to be translated (e.g. linguistics, genre-theory), whereas it is rather criteria internal to the field of translation studies that should be established in order to generate a more meaningful typology, based on the relationship between text and background knowledge.
\end{abstract}

\section{MOTS-CLÉS/KEYWORDS}

translation typology, types of translation, background knowledge, interdisciplinarity

\section{Introduction}

The history of translatology as an academic discipline does not coincide chronologically with the history of any of the various translating traditions (cf. Baker 2004:295) or with the act of translating, which is about as old as human communication itself. Translatology is a rather young discipline dating back to the early 1970s, while in the 1950s and 1960s it was treated as a subfield of applied linguistics (cf. Baker 1998:277). Throughout its short history, the new discipline has been determined, influenced and enriched by a great number of neighbouring or seemingly different disciplines. Today, as translatology has established itself as a traditional humanistic discipline and found its place in the curricula of more and more faculties worldwide, scepticism has arisen among scholars as to whether this diversity should be preserved or not. Some think that translatology should become a discipline entirely in its own right; others think that interdisciplinarity is the only way to constantly enrich and keep the discipline alive. Translatology is inevitably interdisciplinary for obvious reasons, but then again this does not entail a blind adoption of concepts from other disciplines just because this has been the tradition so far. The central argument of this paper is that translatology is in need of a solid theoretical background that will guide its interaction with other disciplines. Once such a background is established, the space and limits of the interaction with other 
disciplines will follow automatically. The issue of translation typology is of crucial importance in this regard, as this is an area where the interdisciplinarity of translatology has found a sound expression. Typology is not only a core theoretical issue in any discipline, but also an important point of reference for the interaction of translatology with other disciplines.

This paper should be seen as an attempt to rethink the types of translation. After a short presentation of traditional and recently suggested typologies and the theoretical problems that arise from them, some thoughts on a new model of typology will be presented. The aim is not only to propose criteria for a typology that are internal to the field of translation studies, or translatology, but also to delimit the space in which other disciplines may play their important role. The ultimate aim is to actually confirm the interdisciplinarity of translatology not through the theoretical background of a translation typology but as a result of it.

\section{Existing Typology Models}

Historically, the first distinction of translation types was between "word-for-word" and "sensefor-sense" translation (cf. Bassnett 1991:39). This binarity dates back to Cicero (De optimo genere oratorum), where translation "ut interpres" (cf. word-for-word) was described as an opposition to translation "ut orator" (cf. sense-for-sense), and has been maintained ${ }^{1}$ over the centuries, through Luther (Sendbrief vom Dolmetschen) in 1530 to Nida's "formal" vs. "dynamic" equivalence (1964) and Catford's binarity between "literal" vs. "free" translation (1965). This distinction has been the subject of vivid discussion among scholars ever since. There have been numerous approaches from various perspectives, though all lead to the same distinction. According to Chesterman, the most recent version of this distinction is that between "semantic" and "communicative" translation, as proposed by Newmark (1981), where a "semantic translation is closer, more literal" (Chesterman 2000:49), while "communicative translation is freer, and gives priority to the effectiveness of the message to be communicated" (ibid.). Nevertheless, Nord's (1988 \& 1997) distinction between "documentary" (dokumentarischer) and "instrumental" (instrumenteller) translation seems to be the latest contribution to the word-sense opposition, with documentary translation entailing a word-for-word and instrumental translation a functionallyoriented rendering. In both cases, it is the translation commission (Übersetzungsauftrag) that determines the choice of type. As Nord herself puts it, it is exactly this dependence on the translation commission that creates the difference to other similar distinctions (cf. 1999:142).

A closely related distinction has been drawn between "foreignizing" and "domesticating" translation, which is again a binary model. Historically, the latter was propagated by the Romans, implying a freer translation so that the outcome can read as an original. The former type, propagated by Schleiermacher $\left(19^{\text {th }}\right.$ century $)$, implies a literal translation where the outcome respects the original in order to let the original word come across as a way of enrichment of the target culture/audience. However, the connection has never been explicitly stated between the "domesticating" type and free (i.e. sense-for-sense) translation on the one hand or between the "foreignizing" type and literal (i.e. word-for-word) translation on the other. The latest debate on this issue includes the distinctions by House (1977) between "overt" and "covert" translation, with overt implying the "foreignizing" type and covert the "domesticating" one (cf. also Schneider 1985) and finally between "direct" and "indirect" translation (Gutt 1991).

Apart from the binary models, there has also been a wide range of classifications containing more than two type ${ }^{2}$. The multidimensional models most widely discussed in translation theory are object-oriented, as opposed to process-oriented, binary ones. While process-oriented models classify translation according to "how" texts are translated in terms of method, object-oriented models take the "what" of the translation, i.e. the texts themselves, as a classification criterion (cf. also Schreiber 1999:151); the latter criterion ultimately translates as text-type or genre. These classifications are strongly influenced by text linguistics and stylistics and they are based on traditional classifications of language functions (Bühler 1934, Halliday 1973). Reiss and Vermeer (1984) argue that the translation method depends on the type of the text as well as on the purpose that its translation serves. The suggested types of texts (cf. Reiss 1976:12) are examined together with purpose and lead to different types of translation. 
An approach based on reversibility, i.e. the possibility of achieving through back-translation a text that is the same as the original, is proposed by Folkart (1989:20). The outcome comprises four different types, the first (mathematical texts) being characterised by the highest reversibility, the second (technical texts) and the third (constrained texts) by medium reversibility and the fourth (general and literary texts) by the lowest reversibility. Sager (1998:70) discusses a wider range of criteria such as the existence (or absence) of situational antecedents in the target culture; the familiarity of the target language text type in the target culture; the purpose of the translation; the relative status of the source and target texts; the awareness (or absence of awareness) by the reader that the target text is a translation and, finally, the existence (or absence) of standardized solutions. His classification argumentation results in a three-dimensional model (Bible, literary and nonliterary translation). The bibliography on text-type oriented classifications of translation is extensive (cf. for example Trosborg 1997 and Snell-Hornby et al. 1999:205). These models have had an immense impact on the contemporary practical understanding of the types of translation, as shown in the curricula of most translation institutes worldwide, where translation is taught in respective modules, distinguishing between literary, technical, economic or legal translation.

Yet another different approach is offered by Schreiber (1999:152) who proposes three different types of translation: "text translations" (Textübersetzungen) stress the importance of textinternal invariants and aim at achieving a balance between "cultural foreignization" and "interlingual domestication", while "situational translations" (Umfeldübersetzungen) bring forward text-external invariants, e.g. original textual meaning, cultural function or effect. In contrast to these, the third type implies intentional changes and it is called "interlingual revision" (interlinguale Bearbeitung). Schreiber proposes concrete procedures for all three types.

The latest suggestion regarding multidimensional models is made by Chesterman (2000:54), who discusses a very detailed set of criteria/variables, including equivalence, target language, translator and situational variables, in order to constitute a set of translation types, which will contribute to better communication between the translator and his/her client, and can best be examined in the framework of the sociology of translation.

\section{Discussion and Prerequisites for a Typology of Translation}

The premise of the present paper is that a typology of translation has to be process-oriented. This does not entail that the object of translation is of no importance for translation, but the main objective of a translation typology is to offer an insight into how languages and cultures are rendered rather than into what is being rendered. This restriction is brought about by the fact that object-oriented approaches, like multidimensional models based on text-types, do not necessarily imply any distinguishing procedural differences. For example, it is unclear why a distinction between "technical" and "economic" translation or a distinction between "biblical" and "literary" translation have to be maintained, as there obviously exist many similarities between the types, if not also between the two sets of types (terminology, formal characteristics, background knowledge management etc.). As long as a typology primarily implies a distinction, the logical assumption would be that type and function, as in models suggested by Reiss/Vermeer (1984), Nord (1988) and Sager (1998), are not suitable criteria for a classification of translation, because even in texts of different functions the process of their translation may still display similarities.

An equally significant problem could be detected with typologies based on the criterion of purpose of translation only. Here theory has to take into account the issue of choice, either on the part of the commissioner of the translation or on the part of the translator him-/herself. The question whether the function of the translation will remain constant or not is rather a question of choice imposed by various factors such as situation, personal preference etc. However, I argue that a typology needs invariant differentiation criteria and not criteria of possible differentiation, subject to choice/preference. In a typology based on purpose, which has to be defined before the translation, the process of translation is excluded from a classification effort. Thus, approaches that are based on text-types or genres seem to be rather partial, as they only focus on source- and target text or on criteria inherent to these texts and not to the process itself. 
The approach suggested by Folkart (1989) uses the criterion of reversibility, which implies that the degree of reversibility depends on specific characteristics of the source text, such as technical content or cultural specifics. Although this approach also results in a text-type oriented distinction of translation types, its implications are very interesting for the model proposed below.

The model proposed by Schreiber (1999) again raises the problem of choice presented above. The third type (interlingual revision) constitutes a type strongly dependent on choices about intentional changes in the translation. Thus the translation process is not primarily involved in this part of the classification, while the other two types seem to imply the involvement of important criteria, such as "cultural foreignization" and "cultural domestication", which brings us back to the process-oriented binary models discussed above. If we assume that "foreignization" implies a "word-for-word" translation and "domestication" a "sense-for-sense" one (cf. above), then the binary approaches can be reduced to a word-sense opposition ${ }^{3}$. The major problem arising with respect to this opposition is the degree to which each type is to be used in a text, in other words the degree of literalness. This is a problem that has been widely recognised and is subject to extensive debate (cf. for example Reiss 1985, Venuti 1998, Robinson 1998, Nord 1999, Chesterman 2000). Nevertheless, despite what is commonly expressed in any contemporary translation theory about the necessity of keeping the balance between the source and the target text, i.e. of being equally committed to the source as well as to the target text, there seems to be no sufficient explanation as to the degree to which each type should be applied in a text ${ }^{4}$. In order to justify the application of each type, related disciplines such as theoretical linguistics, cultural studies, intercultural communication and even psychology have been consulted, but this has often lead to controversial understandings of translation. At first sight, this seems, and indeed is, healthy. Yet, some common ground needs to be established, where views will emerge and where interdisciplinarity can function within a clearly set framework, not risking causing controversies. After all, it is not a coincidence that there has not been any widely accepted definition of translation yet.

The above discussion results in the following set of premises for a translation typology. In short, a translation typology should:

- distinguish different types with a process-oriented instead of an object-oriented background; - be based on invariant differentiation criteria, which are not subject to choice/preference (on the part of the translator or translation commissioner);

- make explicit the conditions under which each specific type is to be applied;

- provide a concrete framework for the interaction with related disciplines.

In the model presented below, an attempt will be made to provide a classification criterion and a set of types that will correspond to the premises outlined above.

\section{The Proposed Typology}

Instead of type, function, purpose etc, in the proposed approach background knowledge will be adopted as the criterion according to which types will subsequently be distinguished. The functionality of this criterion will be discussed after the presentation of the various types. However, a few theoretical assumptions must be made beforehand.

\subsection{Theoretical Background}

The essential idea behind the typology to be proposed is that the text interacts with background knowledge within an organized setting. Inspired by the conception of a "textual world", provided by De Beaugrande and Dressler $(1981)^{5}$, according to which background knowledge exists in the form of written or oral texts that interact and affect one another, Gerzymisch-Arbogast and Mudersbach (1998), in their description of holistic systems of knowledge in translation, draw an abstract distinction between two different levels of observation. The first one is the SYSTEM-level, where knowledge is located, the other one is the TEXT-level, where this knowledge is manifested, taking the form of texts. While the fact that knowledge can be approached in a systematic way will be left out of the framework of the present analysis, the important aspect is that text and background 
knowledge can be observed simultaneously as interacting entities in the translation process. Another important aspect is that knowledge is taken to be a wide notion, encompassing all possible information that interacts with the text, either in terms of associations or in terms of information needed for the understanding of the text, concerning both form and content. This information may range from theoretical linguistic background knowledge through to technical, cultural, situational and pragmatic one. The reason for taking linguistic knowledge together with other forms of background knowledge is that language, when viewed as a system, also constitutes an abstract entity outside the text (SYSTEM-level), being partially manifested in the text through lexical items, syntax, semantic relations etc.

Schematically, the distinction between SYSTEM-level and TEXT-level can be depicted as follows:

Picture 1: Distinction between SYSTEM-level and TEXT-level

$$
\text { SYSTEM -level }
$$

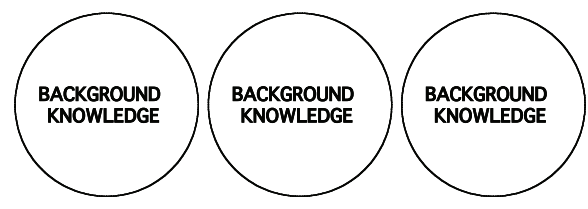

TEXT-level

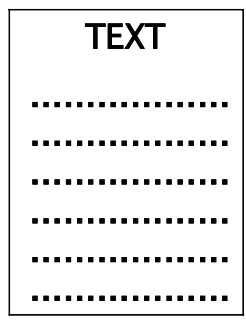

The upper level of the picture (SYSTEM-level) is the level where different forms of background knowledge are located (circles). The lower level is the level where this background knowledge (or parts of this knowledge) is manifested in form of a text. This scheme is not limited to translation but it is a general one, depicting the interaction of any text with the relevant background knowledge.

On the basis of the above depiction, three different types of translation will be distinguished below, and the schemes will accordingly be altered to account for a translation situation, where the Source Text (ST) is embedded in the Source Culture (SC) and the Target Text (TT) is embedded in the Target Culture (TC).

\subsection{The Types}

\subsubsection{Type A: Common Background Knowledge in SC and TC}

Normally, the background knowledge is in most cases considered to be different depending on the culture; however, the analysis of a ST during the translation process reveals that the background knowledge needed for understanding a ST in the SC and the background knowledge needed for producing the respective TT in the TC are identical. This is the case of scientific domains or domains of nature, such as physics, biology, mathematics etc. The information concerning such domains reflects culturally invariable data, so the same knowledge needed for understanding the ST is also used to produce the TT. The only culturally variable aspect here is language, specifically terminology. The translation here mostly results in a word-for-word rendition (cf. section 2 above). This type encompasses highly scientific or highly technical texts, as well as some texts produced by the European Union (EU), where the background knowledge should be common to all member states $^{6}$. Type A can be depicted as follows: 
Picture 2: Type A: Common background knowledge in SC and TC

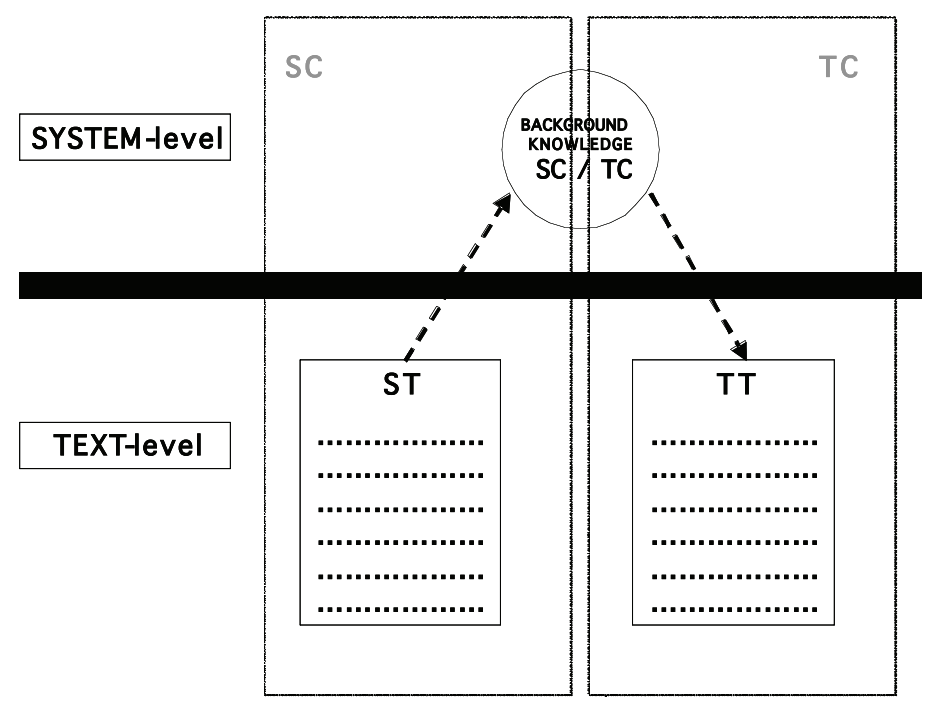

The above picture makes clear the distinction between the two levels of observation and also the distinction between SC and TC, where ST and TT are embedded respectively. There is only one circle for the background knowledge (positioned in between the SC and the TC), signifying the fact that the same knowledge is used both for understanding the ST and for producing the TT. While rendering the ST into a TT, the translator has to cross over to the SYSTEM-level, identify the knowledge needed for understanding the ST and then try to further identify the knowledge needed for producing the TT (trajectory described by the arrows). In the above case, of course, the translator identifies both kinds of background knowledge as identical.

\subsubsection{Type B: Different Background Knowledge in SC and TC}

This is the case most frequently encountered in translation. The background knowledge needed for understanding the ST is different from the background knowledge needed to produce the TT. This is usually the case of literature, advertisements and press articles, where information included in background knowledge reflects culturally variable data. The depiction of this type is the following:

Picture 3: Type B: Different background knowledge in SC and TC

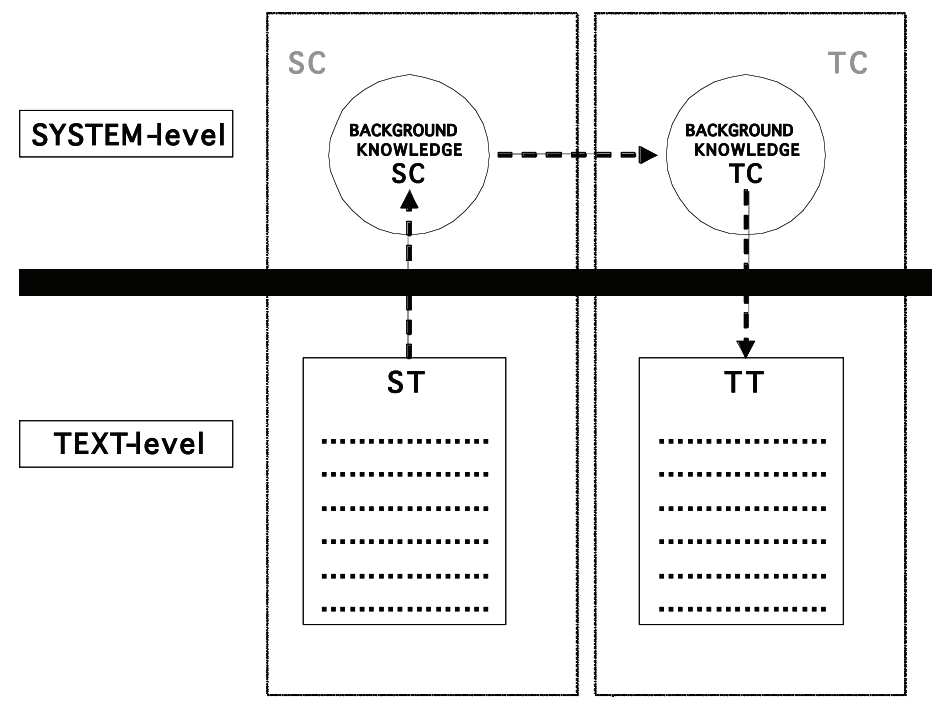


While following a trajectory similar to the one of Type A (described by the arrows), the translator identifies the knowledge needed for understanding the ST and the knowledge needed for producing the TT as non-identical. So, before proceeding with the production of a TT, the translator has to undertake a comparison between the SC-knowledge and the TC-knowledge. This comparison, signified by the horizontal arrow in the picture above, is an implicit one, taking place on the SYSTEM-level. The translation process usually results in a sense-for-sense rendering, or "free" rendering (cf. section 2 above), not excluding the so-called "adaptation" (cf. Koller 1979/1997, Bastin 2004).

\subsubsection{Type C: Non-Existing Background Knowledge in the TC}

Type $\mathrm{C}$ seems to be the most challenging one in translation. This is a case where, although there is background knowledge in the SC for understanding the ST, there is no respective background knowledge in the TC at all. This happens with instances of "idioculture" (Mudersbach 2001:187, cf. also Floros 2005), i.e. when the text contains manifestations of the idiosyncratic style or of notions and ideas of a specific author, as often encountered in poetry and other literary texts. This also happens in cases of "enculturation" and "acculturation" (cf. Katan 1999), i.e. when a new idea or concept exists in a culture (and consequently in a text), but not in other cultures, and it is through translation that the other cultures get acquainted with or even adopt these new ideas or concepts (computer terminology, for example). Thus, the culture where the original idea exists becomes the SC and the culture where this new idea is "transplanted", becomes the TC. Thus, the translator finds him-/herself in the happy yet simultaneously precarious situation of being responsible for the above mentioned "transplantation". So, while he/she is aware of the background knowledge required for understanding the ST, which contains the original idea, he/she is unable to identify any background knowledge in the TC (circle with question mark in Picture 4 below). Consequently, the translator is left with the SC background knowledge, on the basis of which he/she will have to produce/create a TT (arrow pointing from circle to TT in Picture 4 below). The depiction of Type $\mathrm{C}$ looks as follows:

Picture 4: Type C: Non-existing background knowledge in the TC

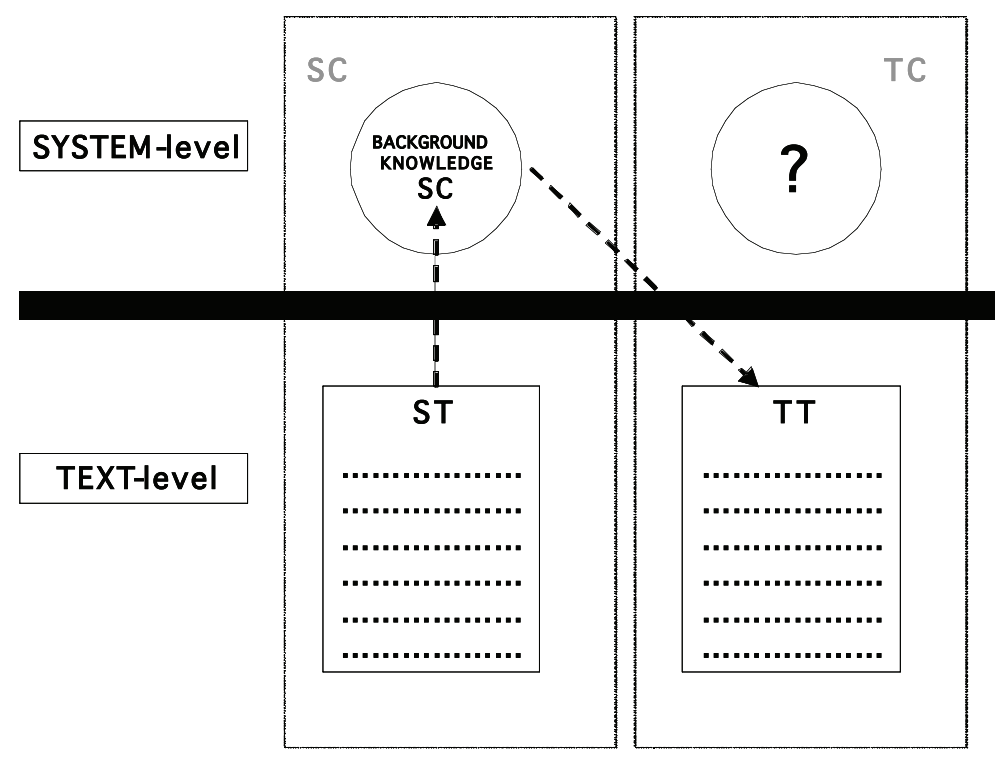

In Type $\mathrm{C}$, the translation process may result either in a word-for-word or in a free rendering, subject to the strategy and choices the translator will follow in the reproduction phase. In theoretical terms, Type $\mathrm{C}$ encompasses literary as well as highly scientific texts, provided that they contain 
idiocultural manifestations or new (in the sense of original) ideas to be rendered into a different language.

\subsection{Discussion}

With respect to the set of premises for a translation typology outlined in section 3 , the proposed typology, which distinguishes three different types of translation on the basis of the interaction of texts with background knowledge, offers the following arguments:

- As regards the distinction of different types with a process-oriented instead of an objectoriented background, the proposed typology clearly focuses on the process of translation followed by the translator, who has to start with the understanding of the ST and proceed through the identification of background knowledge on the SYSTEM-level to the production of a TT on the TEXT-level. As a result, types of translation are distinguished regardless of text-type and it could be shown that traditionally oppositional text-types may co-exist or be distributed differently (e.g. literary and scientific texts co-exist under Type C and legal texts, traditionally seen as highly specialized texts, are now categorised under Type B, together with advertisements). This, of course, does not imply any resemblance in the very nature of these texts or in the specifics of their transfer, but only a common theoretical approach to them. Furthermore, it has to be stressed that distribution mentioned above is not a definite one, as each individual text may vary both in form and content, causing each time a different distribution in terms of type of translation.

- As regards the invariant differentiation criteria, which should not be subject to choice/preference (on the part of the translator or translation commissioner), the proposed typology suggests background knowledge as the main criterion of differentiation, an aspect always present in the translation process regardless of personal choice.

- As regards the conditions under which each specific type is to be applied, it can easily be assumed that any change in the background knowledge pertaining to either the SC or the TC, will automatically bring about a change of translation type; this voids the uncertainty inherent in traditional binary typologies about the application of types such as word-for-word or free translation.

- Finally, as regards the concrete framework for the interaction with related disciplines, the distinction between SYSTEM-level and TEXT-level, on which all types are based, provides a specific way of locating and interacting with other disciplines which inform translation studies, without the risk of cancelling or replacing purely translational methods. The proposed typology thus shows that every possible neighbouring or other discipline may 'interfere' with translation studies not in terms of methodology but in terms of information source, both for understanding and for producing texts.

At this point it has to be stressed that the three proposed types of translation are characterized by two extremely important features: "mutual suspension" and "co-existence". Mutual suspension occurs when one type of translation cancels the other in the translation of a specific item in the text. This may happen due to the fact that translation works on different levels. If, for example, an item is analysed according to its linguistic features (i.e. using linguistic background knowledge) and it is found to be easily translatable into a different language on the grounds that the same linguistic features can be found in the target language, which means that Type A has been applied (common background knowledge in SC and TC), an analysis of the same item on a different level (e.g. using pragmatic or situational background knowledge) may prove that this item has to be changed on the grounds that the function or the context are different in the TC, which means that Type B has been applied (different background knowledge in SC and TC). This is clearly a case where Type B cancels Type A. If, on the other hand, an item has to be changed on the grounds of different pragmatic background knowledge in order to function in the TC, which means that Type B has been 
applied, but its formal characteristics still have to be preserved (e.g. rhyming), which means that Type A has been applied, then this is a case where Type A cancels Type $\mathrm{B}^{7}$.

Co-existence occurs when different types of translation are applied to the same text. This happens due to the fact that texts very often belong to mixed genres. An advertisement, for example, cannot be translated from beginning to end by applying only Type B, as suggested above, because it may contain terminology or other items for which the background knowledge is common for both the SC and the TC. Consequently, for these specific items, Type A will be applied. The same can happen with a literary text which contains elements of social culture together with idiocultural elements. In this case, Type B (different background knowledge to account for differences in social culture) is applied together with Type $\mathrm{C}$ (non-existing background knowledge) in the same text.

\section{Conclusion}

The three types of translation described above present a distinction drawn for methodological reasons. This distinction is actually intended for the didactics of translation, where students have to be introduced to the various ways and conditions of rendering a ST into a TT and also have to be shown that interdisciplinarity in translation studies does not necessarily imply the automatic adoption of methodologies from other disciplines. As the present analysis is still at an initial stage, the proposed translation typology is certainly subject to further refinement. Nevertheless, it could serve as the basis for a critical discussion of traditional theories and methods in the field of translation and it could also be examined in terms of its applicability to different modes of Interpreting.

\section{NOTES}

1. There is, however, the exception of John Dryden's typology (1680), containing three, instead of two, different types of translation: "metaphrase" equals word-for-word translation, "paraphrase" equals sense-for-sense translation and "imitation" entails the abandonment of the original text as the translator sees fit (cf. Bassnett 1991:60).

2. Historically, the first model that ought to be mentioned here is the one by Jakobson (1959), who distinguished between "intralingual", "interlingual" and "intersemiotic" translation. Nevertheless, this model will not be considered further in this article, as the typology issue discussed here only pertains to the translation between different languages and not between different forms of the same language or between semiotic systems.

3. Identifying parallels between "foreignization" and "word-by-word" and between "domestication" and "sense-forsense" translation is admittedly a daring move. However "foreignization" and "domestication" are taken here not as overall approaches or coherent plans of action (cf. Delisle et al. 1999:192) to be decided before the actual process of translating, but as translation methods that can be applied interchangeably during the translation process.

4. This becomes particularly evident in translation didactics, an issue inevitably linked with the theoretical aspect of typology. However, this issue will not be discussed further in this paper.

5. Also discussed later in Neubert (1991).

6. These EU-texts are also known as parallel texts (cf. Floros 2004).

7. In fact, the lack of realization of this mutual suspension is accountable for a lot of translation errors made by unprofessional translators, especially in the field of subtitling, where horrible word-for-word renditions of idiomatic expressions prevent the target audience from understanding the original.

\section{RÉFÉRENCES}

BAKER, M. (1998): “Translation Studies”, in BAKER, M. (ed.): Routledge Encyclopedia of Translation Studies, London, Routledge, p. 277-280.

BAKER, M. (ed.) (2004): Routledge Encyclopedia of Translation Studies, London, Routledge.

BASSnETT, S. (1991): Translation Studies, London \& New York, Routledge.

BASTIN, G. (2004): “Adaptation”, in BAKER, M. (ed.): Routledge Encyclopedia of Translation Studies, London, Routledge, p. 5-8. 
DE BeAugrande, R.-A. and W. U. Dressler (1981): Einfiihrung in die Textlinguistik. Konzepte der Sprach-und Literaturwissenschaft, Tübingen, Niemeyer.

BüHLER, K. (1934): Sprachtheorie: Die Darstellungsfunktion der Sprache, Jena, G. Fischer.

CATFORD, J. C. (1965): A Linguistic Theory of Translation: An Essay in Applied Linguistics, London, Oxford University Press.

Chesterman, A. (2000): "Translation Typology", in Veisbergs, A. and I. ZAuberga (eds.): The Second Riga Symposium on Pragmatic Aspects of Translation, Riga, University of Latvia, p. 49-62.

Delisle, J., H. LeE-JAHnKe and M. C. CORMIER (eds.) (1999) : Terminologie de la Traduction. Translation Terminology. Terminología de la Traducción. Terminologie der Übersetzung, Amsterdam \& Philadelphia, Benjamins.

Floros, G. (2004): "Parallel Texts in Translating and Interpreting", Translation Studies in the New Millennium 2 , p. 33-41.

Floros, G. (forthcoming): "Towards Identifying the Notion of Idioculture in Texts", in HeINE, C., K. SCHUBERT and H. GERZYMisCH-ARBOGAST (eds.): Text and Translation: mit ausgewählten Beiträgen zur EU High Level Scientific Conference (Series) Translation Theory and Methodology 2004, St.Ingbert, Röhrig Universitätsverlag. FOLKART, B. (1989): "Translation and the Arrow of Time", TTR 2-1, p. 19-50.

GerZymisch-ARboGAst, H. and K. MudersbaCH (1998): Methoden des wissenschaftlichen Übersetzens, Tübingen \& Basel, Francke.

GutT, E. A. (1991): Translation and Relevance. Cognition and Context, Oxford, Blackwell.

HallidAy, M. A. K. (1973): Explorations in the Functions of Language, London, Arnold.

House, J. (1977): A Model for Translation Quality Assessment, Tübingen, Narr.

JAKOBSON, R. (1959): “On Linguistic Aspects of Translation”, in Brower, R. (ed.): On Translation, Cambridge, Mass., Harvard University Press, p. 232-239.

Katan, D. (1999): Translating Cultures. An introduction for translators, interpreters and mediators, Manchester, St. Jerome.

KOLLER, W. (1979/1997): Einführung in die Übersetzungswissenschaft, Heidelberg \& Wiesbaden, Quelle \& Meyer. MudersBaCH, K. (2001): „Kultur braucht Übersetzung. Übersetzung braucht Kultur. (Modell und Methode)”, in Thome, G., C. Giehl and H. GerZYMisch-ArbogAST (eds.): Kultur und Übersetzung: Methodologische Probleme des Kulturtransfers, Tübingen, Narr, p. 169-226.

NEUBERT, A. (1991): “Translation across Languages or across Cultures?”, in JANKOwsKY, K. R. (ed.): Scientific and Humanistic Dimensions of Language: Festschrift for Robert Lado on the Occasion of his 70th Birthday on May 31, Amsterdam, Benjamins, p. 231-239.

Newmark, P. (1981): Approaches to Translation, Oxford, Pergamon Press.

NidA, E. A. (1964): Toward a Science of Translating, Leiden, Brill.

NORD, C. (1988): Textanalyse und Übersetzen, Heidelberg, Groos.

NoRD, C. (1997): Translating as a Purposeful Activity: Functionalist Translation Theories Explained, Manchester, St. Jerome.

NoRD, C. (1999): "Das Verhältnis des Zieltexts zum Ausgangstext", in SNELl-HornBy, M. et al. (eds.): Handbuch Translation, Tübingen, Stauffenburg, p. 141-144.

REIß, K. (1976): Texttyp und Übersetzungsmethode: Der operative Text, Kronberg \& Taunus, Scriptor.

REIß, K. and H. J. VERMEER (1984): Grundlegung einer allgemeinen Translationstheorie, Tübingen, Niemeyer.

REIß, K. (1985): "Paraphrase und Übersetzung”, in GNILKA, J. and H. P. RÜGER (eds.): Die Übersetzung der Bibel, Bielefeld, Luther-Verlag, p. 272-287.

RobInson, D. (1998): "Free Translation", in BAKER, M. (ed.): Routledge Encyclopedia of Translation Studies, London, Routledge, p. 87-90.

SAGER, J. (1998): "What Distinguishes Major Types of Translation?”, The Translator 4-1, p. 69-89.

SCHNEIDER, M. (1985): “Zwischen Verfremdung und Einbürgerung”, Germanisch-romanische Monatsschrift 66, p. $1-12$.

SCHREIBER, M. (1999): "Übersetzungstypen und Übersetzungsverfahren”, in SNELL-HORNBY, M. et al. (eds.):

Handbuch Translation, Tübingen, Stauffenburg, p. 151-154.

Snell-Hornby, M., H. G. Hönig, P. Kussmaul and P. A. SchmitT (eds.) (1999): Handbuch Translation, Tübingen, Stauffenburg.

Trosborg, A. (ed.) (1997): Text Typology and Translation, Amsterdam, Benjamins. 
VEnUti, L. (1998): "Strategies of Translation”, in BAKER, M. (ed.): Routledge Encyclopedia of Translation Studies, London, Routledge, p. 240-244. 